\title{
EL PENSAMIENTO SOCIAL DE LUIS VIVES INTERPRETADO POR JOAQUÍN COSTA
}

Francisco Calero

UNED. Madrid

\section{RESUMEN}

El presente trabajo tiene como finalidad hacer un comentario crítico de algunos puntos de vista de Joaquín Costa acerca de las obras de Vives De subventione pauperum' y De communione rerum. Para ello iremos citando los párrafos más significativos del estudio contenido en su obra Colectivismo agrario en España ${ }^{2}$, y a continuación haremos nuestras propias apreciaciones. No es este el lugar adecuado para pasar revista a las diversas interpretaciones del pensamiento costiano, pero sí parece oportuno remitir al lector interesado en las mismas a la reciente obra de Alfonso Ortí ${ }^{3}$.

1 Las citas de ambas obras se hacen por la edición de Gregorio Mayans Opera omnia distributa et ordinata in argumentorum classes praecipuas... 8 vols. Valentiae, in officina B. MONFORT, 1782-1790. La primera se encuentra en el vol. IV y la segunda en el V. La traducción es del autor del presente trabajo.

2 Costa, J., Colectivismo agrario en España. Parte I y II. Doctrinas y hechos. Madrid, Imprenta de S. Francisco de Sales, 1898. Las citas se hacen por la edición de Biblioteca Costa, 1915.

${ }^{3}$ Ortf. A., En torno a Costa. Madrid, Ministerio de Agricultura, Pesca y Alimentación, 1996. 
Las ideas de carácter social de Vives se encuentran fundamentalmente en De subventione pauperum (1526) y De communione rerum (1535), dos obras muy diferentes tanto por su origen como por su finalidad. La primera fue emprendida por insinuación de Luis de Praet, a la sazón embajador de Brujas en Inglaterra, y tiene como finalidad solucionar el problema de la mendicidad en la ciudad flamenca; la segunda tuvo su origen en los gravísimos problemas ocasionados por los anabaptistas, y pretende hacer cambiar de parecer a los que de buena fe se habían adherido a tal movimiento.

Las ideas sociales de De subventione pauperum son, sin ninguna duda, muy avanzadas, hasta el punto de haber sido interpretadas como socialistas por Alain Guy ${ }^{4}$ y como comunistas por Víctor Sanz ${ }^{5}$. Por el contrario De communione rerum fue alabada como la primera obra anticomunista por Wenceslao González Oliveros ${ }^{6}$. Hasta tal punto son diferentes dichas obras que Joaquín Costa escribe: «cuesta trabajo pensar que ambas obras hayan salido de una misma pluma, aun tomada en cuenta la diferencia de circunstancias y de fechas en que se produjeron' ${ }^{7}$. Es comprensible por ello que De subventione y De communione hayan podido ser tomadas como bandera de posiciones antitéticas.

Antes de entrar en las interpretaciones de Costa, es conveniente conocer en sus propias palabras qué entiende por colectivismo agrario: «El colectivismo agrario es una atenuación de aquél; presume realizar todos esos bienes, conseguir todos esos beneficios, sin socializar el capital. Respeta y mantiene en los mismos términos de ahora la propiedad privada no tan sólo de los productos del trabajo, ó sea de los objetos de consumo, sino también de los instrumentos de producción, con la sola excepción de uno: el suelo, ó sea la tierra. La propiedad individual no puede legítimamente recaer sino sobre bienes que sean producto del trabajo individual; la tierra es obra exclusiva de la Naturaleza: por consiguiente, no es susceptible de apropiación» ${ }^{8}$.

También es conveniente poner de relieve la alta estima que Costa tenía de la obra de Vives De subventione pauperum, a la que no sólo considera origen de la sociología española junto con De rege et regis institutione del $\mathrm{P}$. Mariana, sino que la coloca entre los libros más nobles: «Sin arranques de innovador, con aquella templanza y moderación que son la característica de su genio

4 GuY, A., Vivès ou l'humanisme engagé. Paris, Seghers, 1972.

5 SANZ, V., Vigencia actual de Juan Luis Vives. Montevideo, Universidad de la república, 1967.

- González Oliveros, W., Humanismo frente a comunismo. El primer libro anticomunista publicado en el mundo, obra de un pensador español. Valladolid, Imprenta Luis Calderón, 1937.

7 Costa, J., Colectivismo agrario en España, p. 52.

${ }^{8}$ Costa, J., Colectivismo agrario en España, pp. 3-4. 
medido, circunspecto y equilibrado, sembró Vives en uno de los libros más nobles que han brotado de pluma humana, un esbozo diminuto de sociedad ideal, que recuerda el grano de mostaza del Evangelio, sin sospechar que en él iba contenido un árbol de tan frondosa copa como ahora principiamos nosotros á entrever" ${ }^{9}$. Ciertamente el tratado de Vives tuvo honda repercusión en Europa durante el siglo XVI, pero fue olvidado durante los siglos XVII, XVIII y XIX, con la sola excepción de Gregorio Mayans, bajo cuyos auspicios se editó la traducción entonces descubierta de Nieto Ivarra ${ }^{10}$. Por eso Costa tiene el mérito de haber redescubierto a finales del XIX la extraordinaria importancia del $D e$ subventione pauperum.

I. «Da por sentado este libro que el estado primitivo de la sociedad humana fue la comunidad de bienes» " ${ }^{1}$. Esta apreciación me parece correcta, ya que es perceptible en Vives una cierta nostalgia de comunismo originario. Se puede comprobar en el siguiente texto:

«Hasta entonces ciertamente vivían perfectamente y en concordia, pero un viejo mal agitó a muchos con el afán de sobresalir sobre los demás o, mejor, de oprimirlos, para que sin trabajar y honrados disfrutasen de los trabajos ajenos y los demás ejecutasen sus órdenes» ${ }^{2}$.

También es perceptible dicha nostalgia en De communione rerum:

«Queréis que todas las cosas sean comunes: guardemos silencio sobre el estado del hombre sin culpa, que llaman de inocencia; hablemos de esta naturaleza nuestra inclinada al vicio y a todos los males" ${ }^{13}$.

«Si quitas de los hombres esos impulsos del ánimo que se llaman pasiones, quizás lleves a cabo la comunidad de bienes» ${ }^{14}$.

II. «En General, parece poco inclinado [Vives] á que los bienes de los padres se transmitan á los hijos» ${ }^{15}$. También está bien fundamentada esta afirmación de Costa, que puede ser apoyada en varios pasajes de De subventione pauperum:

${ }^{9}$ Costa, J., Colectivismo agrario en España, p. 28.

10 Tratado del socorro de los pobres compuesto en latín por el Doctor Juan Luis Vives. Traducido en castellano por el Dr. Juan de Gonzalo Nieto Ivarra. Valencia, BENITo MonforT, 1781. Esta traducción fue recogida en el volumen LXV de la Biblioteca de Autores Españoles, Madrid, 1873, donde Costa la conoció.

"Costa, J., Colectivismo agrario en España, p. 33

12 VIVES, J.L., De subventione pauperum, p. 424.

1.3 VIVES, J.L., De communione rerum, p. 473.

14 VIVES, J.L., De communione rerum, p. 477.

15 Costa, J., Colectivismo agrario en España, p. 35 
"Acaso no quieres dejarles ninguna preocupación? ¿No les dejas nada para hacer o para ejercitarse? Pésimamente, sin duda, miras por ellos, y tú mismo no rehúsas vivir pobremente e incluso miserablemente por causa de aquellos de quienes ignoras cómo serán» ${ }^{16}$.

«Dejarás a los hijos abundantemente ricos si han sido instruidos en un buen oficio y en espíritu religioso» ${ }^{17}$.

III. «En este punto, hubo de advertir Vives que no iba por buen camino, toda vez que las mieses, los ganados, las pieles, los bueyes etc., no son pura obra de la Naturaleza; que el arte y el sudor humano tienen tanta parte como ella en tales riquezas; y como si respondiera á esta observación, enuncia una idea que encierra en germen la teoría entera del colectivismo» ${ }^{18}$. Costa escribe estas palabras a propósito del siguiente pasaje de Vives:

«Así, pues, cuántos bienes nos esparció él, ya sea para comer: hierbas, raíces, frutos, cereales, ganados, peces, todos en común, ya para vestir: pieles, lanas; luego maderas y metales; y las ventajas de los animales, como las de los perros, caballos y bueyes. Finalmente, todas las cosas que nos ofreció las puso en esta casa no cerrada por ninguna valla o cerrojo, comunes a los seres que engendró. Dime tú que eres propietario ¿eres más hijo de la naturaleza que yo? Si no lo eres, ¿por qué me excluyes, como hijo legítimo de la naturaleza a un bastardo? Pero dices: he empleado mi trabajo y laboriosidad, permítaseme también poseer, yo haré lo mismo» ${ }^{19}$.

Y continúa así: «Apunta aquí vagamente una distinción entre los frutos del trabajo, que cree deben ser del que los produce (siquiera un imperativo moral le obligue á comunicarlos con sus hermanos necesitados) y el instrumento que la Naturaleza pone á disposición de todos para que produzcan y cuya posesión no juzga lícito monopolizar» ${ }^{20}$. A esta argumentación se puede oponer que $\mathrm{Vi}$ ves no hace tal distinción entre la tierra y los productos del trabajo y que, por tanto, no está justificado ver en sus palabras el germen del colectivismo. Creo que en este caso Costa hace la interpretación del texto vivista bajo la influencia de unas ideas preconcebidas. Vives admite la propiedad sin hacer distinciones en De subventione, a pesar de que lo nieguen algunos estudiosos, como

\footnotetext{
16 VIVES, J.L., De subventione pauperum, Pp. 446-447.

17 VIVES, J.L. De subventione pauperum, p. 447.

in Costa, J., Colectivismo agrario en España, p. 36.

19 VIVES, J.L., De subventione pauperum, p. 451.

20 Costa, J., Colectivismo agrario en España, p. 36.
} 
Víctor Sanz ${ }^{21}$ y Alain Guy ${ }^{22}$. Como argumento puede servir el título del capítulo IX de la primera parte «Los bienes que a cada uno le da Dios no le son dados sólo por sí mismo» ${ }^{23}$, por el que claramente admite Vives que Dios da determinados bienes a cada persona.

IV. «La consecuencia práctica de aquella distinción [bienes del trabajo y tierra] sería reponer las cosas al estado que tenían la víspera del primitivo reparto de tierras, restableciendo el derecho igual de todos á los beneficios de la naturaleza. No arredró esta conclusión a Vives» ${ }^{24}$. Fundamenta Costa esta afirmación en el siguiente texto de Vives:

"Así como en la ciudad se renuevan todas las cosas, que se cambian o perecen por el paso del tiempo o por contingencias (muros, fosos, parapetos, arroyos, instituciones, costumbres, incluso leyes), de la misma forma sería adecuado ir en ayuda de la primitiva distribución del dinero, que recibió quebrantos de varios modos» ${ }^{25}$.

El nuevo reparto de las tierras, defendido por Costa, podía deducirse analógicamente de la redistribución del dinero, propugnada por Vives, pero Costa señala que pecunia (dinero) está utilizado en lugar de agri (tierra) ${ }^{26}$, lo que no es correcto, ya que Vives había tratado expresamente de la distribución del dinero:

«Estas monedas fueron acuñadas al principio de alguna forma en gran cantidad, siendo repartidas entre los ciudadanos para que cada uno negociase con ellas, las diese por los trabajos o cosas de otros y, a su vez, las recibiese por los suyos, de este modo conservase mediante una actividad honesta sus facultades vitales y, equilibrados los oficios de la ciudad por los intercambios, cada uno consolidase su patrimonio» ${ }^{27}$.

«Sabido es, por otra parte, que esta doctrina, de tan noble y lejano abolengo ${ }^{28}$, que había quedado sepultada en el olvido, sin ulterior desarrollo, por no serle favorable el medio social acaba de rebrotar del modo más inesperado, predicada casi á la misma hora, desde los más opuestos campos, por varones

21 En su libro Vigencia actual de Juan Luis Vives.

22 En su libro Vives ou l' humanisme engagé.

21 VIVES, J.L., De subventione pauperum, p. 450.

24 Costa, J., Colectivismo agrario en España, p. 37

${ }^{25}$ VIVES, J.L., De subventione pauperum, p. 468.

${ }^{26}$ Costa, J., Colectivismo agrario en España, p. 41.

27 VIVES, J.L., De subventione pauperum, p. 425.

${ }^{28}$ Se refiere Costa a que algunos padres de la Iglesia defendieron ya la doctrina sobre la función social de la propiedad. 
de tanta autoridad como el opulento industrial y filántropo norte-americano Andrés Carnegie y el egregio estadista Gladstone, en su «Evangelio de la riqueza», el venerable pontífice León XIII en su encíclica Rerum novarum, el cardenal Manning, de tan gloriosa memoria, el gran rabino Hermann Adler, y otros. Lo mismo que el filósofo de Valencia hace cuatro siglos, juzgan ellos que el hombre acaudalado no debe mirar sus riquezas como propias, sino como comunes, considerándose mero depositario de ellas y administrador de los pobres, á los cuales debe destinar todo el sobrante después de satisfechas las necesidades propias y las de su familia, requeridas por una vida modesta y sin ostentación» ${ }^{29}$.

A pesar de que la tesis fundamental de Costa es que Vives es un precedente del colectivismo agrario, también defiende que Vives recoge la doctrina de la función social de la propiedad, expuesta ya en los albores del cristianismo por los primeros padres de la Iglesia, y recogida en el siglo XIX en diversos medios, de los que nos da precisa información. En esta apreciación estamos totalmente de acuerdo con Costa, y se puede demostrar con dos textos muy claros de Vives:

«Así, pues, que nadie ignore este hecho, que él no ha recibido su cuerpo, su alma, su vida y su dinero para su uso y utilidad exclusivos, sino que es administrador de todos esos bienes y que no los ha recibido de Dios con otro fin» ${ }^{30}$.

«Finalmente es ladrón quien no reparte a los pobres lo que le sobra de las necesidades naturales, $y$, si no es castigado por las leyes humanas, aunque también lo hicieron algunas, con seguridad será castigado por las divinas» ${ }^{31}$.

${ }^{29}$ Costa, J., Colectivismo agrario en España, p. 39.

30 VIVES, J.L., De subventione pauperum, p. 452.

31 VIVES, J.L., De subventione pauperum, p. 453. 